ERC Working Papers in Economics 18/05

March / 2018

\title{
BARGAINING IN LEGISLATURES OVER PRIVATE AND PUBLIC GOODS WITH ENDOGENOUS RECOGNITION
}

\author{
Hakan Genç \\ Department of Economics, Middle East Technical University, Ankara, Turkey \\ E-mail: hgenc@metu.edu.tr
}

Serkan Küçükșenel

Department of Economics, Middle East Technical University, Ankara, Turkey

E-mail: kuserkan@metu.edu.tr 


\title{
BARGAINING IN LEGISLATURES OVER PRIVATE AND PUBLIC GOODS WITH ENDOGENOUS RECOGNITION
}

\author{
Hakan Genç* $\quad$ Serkan Küçükşenel ${ }^{\dagger}$
}

March 9, 2018

\begin{abstract}
This paper studies a sequential model of multilateral bargaining with a majority rule in which legislators can make decisions over both private and public good dimensions with endogenous recognition process. Legislators expend resources to be the proposer and make proposals about the allocation of private and public goods. We show that legislators can exert effort to be the proposer and make proposals in both dimensions depending on legislative preferences. Effort choices in equilibrium mainly depend on preferences over both distributional and ideological dimensions, as well as the patience level of legislators and the size of the legislature. We also show that in a diverse legislature, it may be possible to have distributive policies when the majority has collective desires or vice-versa.
\end{abstract}

Keywords: Multilateral bargaining, majority rule, public goods

JEL Codes: C71, C78, D72,

\footnotetext{
*Department of Economics, Middle East Technical University, Ankara, 06800, Turkey, Email:hgenc@metu.edu.tr; Tel:+90 3122107019

†Department of Economics, Middle East Technical University, Ankara, 06800, Turkey, Email:kuserkan@metu.edu.tr; Tel:+90 312210 3013; Fax:+90 3122107964
} 


\section{INTRODUCTION}

Bargaining in legislatures and its internal dynamics are one of the most significant topics discussed in both game theory and political economy. Especially after Baron and Ferejohn's (1989) seminal contributions to this literature, concepts of coalition formation, the structure of legislation, and voting strategies have been investigated in many papers.

Almost all prior models examine the provision of private and public goods in legislatures separately. In these models, it is hard to see the explicit trade-offs between collective and particularistic policies in a legislation. Baron and Ferejohn (1989) present a private good bargaining model which is adapted to legislatures. Contrary to Rubinstein's (1982) model, legislators are recognized to be proposer randomly- not in a fixed sequence. Their model examines coalition formation and allocation of private goods under closed and open rules. Banks and Duggan (2000) generalize Baron-Ferejohn (1989) model. They prove the existence of stationary equilibria when the set of alternatives is multidimensional. Merlo and Wilson (1995) examine "divide the dollar game" under unanimity rule with a stochastically changeable prize over time. They show that there exists a delay in an equilibrium. Similarly, in Austen-Smith and Banks (1988), particularistic aspects are added to their spatial voting model and they find the equilibrium voting strategies, party positions and legislative policy outcomes. On the other hand, some previous studies capture both particularistic and collective policies. Jackson and Moselle (2002) examine a legislative voting game in which both collective and particularistic policies are included. However, they do not show the explicit provision of public good and private good in their model. Volden and Wiseman (2007) present a sequential bargaining model in which legislators make decisions over both private and public good dimensions with a random recognition process. They present results explaining the explicit trade-offs between private and public good spendings. Moreover, they show that in a diverse legislature, it becomes possible to have particularistic policies or spendings, when the majority have collective desires or vice-versa. However, Volden and 
Wiseman's (2007) model does not include the concept of rent-seeking contest:1. We know that in a rent-seeking environment where bargaining negotiations occur, agents generally exert effort or make investments to be the first proposer. This occurs because of the fact that being a first proposer generally brings an extra surplus in sequential bargaining environments. Yildirim $(2007,2010)$ analyze a sequential bargaining model for particularistic goods where players exert efforts to become the proposer and influence policy decisions. Yildirim (2007) proves the existence of positive effort levels and shows the relationship among the players marginal costs, patience and effort levels under transitory and persistent recognition with different voting rules.

As far as we know, this is the first study on bargaining in legislatures over private and public goods with endogenous recognition (with costly efforts). In our model, legislators expend resources to be the proposer and decide on the allocation of private and public goods. The main results of this study are as follows: In the symmetric case where all legislators are identical, we characterize legislators according to their valuations on private and public goods. Moreover, we present a sub-game perfect equilibrium that specifies the allocation of resources over both ideological and distributive dimensions with optimal effort levels when the legislators are pure collectivist, pure distributive or mixed. The optimal effort level in symmetric case is positively correlated with the valuation of private good spending, and negatively correlated with the number of legislators and legislators' level of patience. In the asymmetric case, in a diverse legislature, we increase the heterogeneity of the legislature by allowing to have two different groups in the legislature. We show all possible equilibrium allocations and effort levels.

The organization of the rest of the paper is as follows: In the next section, we present the model. Section 3 presents the benchmark cases for our main model. Section 4 analyses the symmetric case. Section 5 relaxes the symmetry assumption and characterize the equilibrium

\footnotetext{
${ }^{1}$ See Tullock (2001) for more on rent-seeking contests.
} 
in a diverse legislature. Finally, Section 6 concludes.

\section{THE MODEL}

\subsection{Structure of the Game}

Legislators: Let $N=\{1,2, \ldots, n\}$ be the set of legislators from different legislative districts who are deciding how to divide a fixed amount of a resources among districts. We assume that $|N|=n \geq 3$ and $n$ is odd.

Decisions : A decision is a vector $\left(y, x_{1}, \ldots, x_{n}\right)$ consisting of a ideological decision-public good $y$ and a distributive decision-private good $\left(x_{1}, \ldots, x_{n}\right)$. The set of feasible decisions are those such that $y \geq 0$ and $x_{i} \geq 0$ for all $i$ and $y+\sum_{i \in N} x_{i} \leq 1$. Let $D$ be the set of all

feasible decisions: $D \equiv\left\{\left(y, x_{1}, \ldots, x_{n}\right) \mid \forall i \in N, x_{i} \geq 0, y \geq 0, y+\sum_{i \in N} x_{i} \leq 1\right\}$. Let $d^{i}$ be the decision that legislator $i$ proposes when he is recognized.

Recognition Probabilities: Legislators simultaneously exert irreversible efforts at each step of the legislature. That is, their efforts can be renewed at each round of the legislature. Let $e_{i}$ and $C_{i}\left(e_{i}\right)$ represents legislature $i$ 's effort and its cost respectively. For simplicity, we assume that $C_{i}\left(e_{i}\right)=k_{i} e_{i}$ where $k_{i} \in \mathbb{R}_{+}$for all $i \in N$. Let $p_{i}(e):\left[0, \frac{1}{k_{i}}\right]^{n} \rightarrow[0,1]$ be legislator $i$ 's recognition probability, such that

$$
p_{i}(e)=\left\{\begin{array}{cc}
\frac{e_{i}}{\sum_{j \in N} e_{j}} & \text { if } \vec{e} \neq 0 \\
\frac{1}{n} & \text { if } \vec{e}=0
\end{array}\right.
$$

Preferences : Legislators have preferences over decisions and effort levels. Hence, preferences are represented by a utility function $u_{i}: \mathbb{R}_{+}^{3} \rightarrow \mathbb{R}_{+}$. The utility function, $u_{i}\left(y, x_{i}, e_{i}\right)$ is non-negative, continuous, strictly increasing in $x_{i}$ and strictly decreasing in $e_{i}$. We assume 
that legislator $i$ 's stage utility can be represented as

$$
u_{i}\left(y, x_{i}, e_{i}\right)=\alpha_{i} x_{i}+\left(1-\alpha_{i}\right) y-k_{i} e_{i}
$$

where $\alpha_{i} \in[0,1]$ for all $i \in N$. The discount rate of legislators is denoted as $\delta$ where $0<\delta<1$

\subsection{The Legislative Game}

Let $T=\left\{t \in \mathbb{N} \mid t \leq t^{*}\right\}$ be a potentially infinite number of sessions. At the beginning of session $t=0$, legislators simultaneously expend efforts. Once efforts are chosen, a legislator is recognized with probability $p_{i}(e)$ to propose a decision in each session. Next, the recognized legislator proposes a decision $d^{i}=\left(y^{i}, x_{1}^{i}, \ldots, x_{n}^{i}\right)$. Then, this proposal is the motion on the floor. We assume that amendment rule is closed which implies counter-proposals or amendments to the proposal on the floor are prohibited. Then, each legislator decides whether to accept or reject proposal. If a majority of legislators accept the proposal, then the game ends and the decision is implemented. Otherwise, the game proceeds to next session and the legislators choose their effort levels again and a legislator $j$ is recognized with the probability $p_{j}(e)$ to propose. If a decision $d \in D$ at session $t$ is accepted, legislator

$i$ 's pay-off is given by $\delta^{t}\left(\alpha_{i} x_{i}+\left(1-\alpha_{i}\right) y\right)-\sum_{t^{\prime}=0}^{t} \delta^{t^{\prime}} k_{i} e_{i}$. If no proposal has been approved by the end of the last session, the default decision $\left(\bar{y}, \bar{x}_{1}, \ldots, \bar{x}_{n}\right)$ is implemented. We assume that $\bar{y}=\bar{x}_{i}=0$ for all $i \in N$. Therefore, if no agreement is ever reached, legislature $i$ 's pay-off is given by $-\sum_{t^{\prime}=0}^{\infty} \delta^{t^{\prime}} k_{i} e_{i}$. 


\subsection{Strategies and Legislative Equilibrium}

The game is one of perfect information and the definition of strategies and sub-game perfection are standard. We characterize the stationary equilibria for this game. A strategy is stationary if it is history independent. An equilibrium is stationary if it is sub-game perfect equilibrium and each legislator's strategy is stationary. Stationary sub-game perfect equilibrium (SSPE) can specify identical actions for each continuation of the game. Thus, by reducing the equilibrium set, solving multiple equilibrium problem in multilateral bargaining becomes easier. As a result, since SSPE presents less complex and more analytic equilibria structures, we use stationary strategies and equilibrium. See Baron and Ferejohn (1989) and Jackson and Moselle (2002) for more on this type of equilibrium.

\section{BENCHMARKS}

Our model is closely related to following papers. If $\alpha_{i}=1$ for all $i \in N$ (which implies $y=0$ in equilibrium), the model is equivalent to Yildirim (2007). If the recognition process is exogenous then our model has close connections with the models in Volden and Wiseman (2007), Jackson and Moselle (2002), and Baron and Ferejohn (1989). Suppose the recognition process is exogenous. Then, our model is equivalent to Volden and Wiseman (2007) if the recognition probabilities are uniform. If the ideological and distributive dimensions are not connected through the feasibility constraint for decisions and the recognition process is exogenous, then our model is a special case of Jackson and Moselle (2002). Moreover, if there is no public good decision and the recognition process is exogenous, the model is equivalent to Baron and Ferejohn (1989).

Benchmark 1: ( Baron and Ferejohn (1989)) If $y^{i}=0$ and $e_{i}=0$ for all $i \in N$, then in any stationary equilibrium each legislator has an expected distributive allocation of $\frac{1}{n}$. 
Furthermore, there exists a stationary equilibrium in which any recognized legislator proposes

a share $\left(1-\delta \frac{(n-1)}{2 n}\right)$ for himself, and $\frac{\delta}{n}$ to each of randomly selected $\frac{n-1}{2}$ other legislator, and this is approved by those randomly selected legislators. The first proposal receives a majority vote, so the legislature completes its task in the first session.

This result captures the main idea of sequential bargaining. Legislators are offered a part of surplus which makes them indifferent between voting yes now and waiting for the continuation. In the model, being a proposer has a big advantage since the proposer keeps the excess surplus. Moreover, the recognition process is exogenous which is not related to any institution.

Benchmark 2 : (Yildirim (2007)) If $\alpha_{i}=1$ for all $i \in N$, then under simple majority voting rule with $\delta_{i}=\delta$ and $k_{i}=k$ for all $i \in N$, there exists a unique equilibrium pair of $\left(e^{*}, v^{*}\right)$ such that each $i$ exerts same amount effort with same recognition probability.

Benchmark 2 states that if agents are identical (same patience level with same marginal cost), they have same continuation values $v^{*}$ with same optimal effort level $e^{*}$. In the next section, we start to examine the symmetric case to present the intuition behind costly recognition and the interaction between public good (or collective) and private good (or particularistic) dimensions. In the symmetric case, all legislators have the same characteristics.

\section{SYMMETRIC CASE}

In this section, we assume that legislators are identical $\left(\alpha_{i}=\alpha\right.$ and $k_{i}=k$ for all $\left.i \in N\right)$ and we characterize equilibrium behaviors according to legislators' valuations on private and public goods. The following propositions characterize a unique equilibrium for different values of $\alpha$. Our first result shows that if there is no conflict of interests in the legislature, legislators do not exert effort (which is assumed to be an unproductive activity) to increase 
their probability of recognition.

Proposition 1 : If $\alpha \in\left[0, \frac{1}{2}\right]$ for all $i \in N$, then there exists a unique equilibrium in which the legislative game ends in the first session with a unanimously approved decision that involves only public good dimension, and

- $e_{i}=0$

- $p_{i}(e)=\frac{1}{n}$

- $d^{i}=(1,0, \ldots, 0)$ for all $i \in N$.

The proofs of this and subsequent results are relegated to the Appendix. Proposition 1 states that if legislators highly value public good relative to private good, all available resources will spend on the public good which is non-excludable. This also means that being recognized does not affect the expected payoffs. Therefore, legislators will not expend effort (which is costly) and each legislator is equally likely to propose a decision in equilibrium.

Proposition 2: i) If $\alpha \in\left(\frac{1}{2}, \frac{n(1+\delta+n(1-\delta))}{(3+n) n-\delta\left(n^{2}-1\right)}\right]$ for all $i \in N$, then there exists a unique equilibrium in which the legislative game ends in the first session with a unanimously approved decision that involves both public good dimension and private good dimension such that for all $i \in N$,

$$
\begin{aligned}
& -e_{i}=e=\frac{(n-1)}{n^{2} k}\left(\frac{\alpha(1-\alpha)\left(n^{2}(1-\delta)+\delta n\right)}{\delta \alpha+(1-\alpha)\left(n^{2}(1-\delta)+\delta(n-1)\right.}\right)>0 \\
& \text { - } p_{i}(e)=\frac{1}{n} \\
& \text { - } y^{i}=\frac{\delta \alpha}{\delta \alpha+(1-\alpha)\left(n^{2}(1-\delta)+\delta(n-1)\right)} \\
& \text { - } x_{i}^{i}=\frac{(1-\alpha)\left(n^{2}(1-\delta)+\delta(n-1)\right)}{\delta \alpha+(1-\alpha)\left(n^{2}(1-\delta)+\delta(n-1)\right)} \text { and } x_{-i}^{i}=0 .
\end{aligned}
$$


ii) If $\alpha \in\left(\frac{n(1+\delta+n(1-\delta))}{(3+n) n-\delta\left(n^{2}-1\right)}, 1\right]$, then there exists a unique equilibrium in which the legislative game ends in the first session with an approved decision that involves only private good dimension such that for all $i \in N$,

- $e_{i}=e^{\prime}=\frac{\alpha(n-1)}{n^{2} k}\left(1-\frac{(n-1) \delta}{2 n^{2}-\delta(n-1)^{2}}\right)>0$

- $p_{i}(e)=\frac{1}{n}$

- $y^{i}=0, x_{i}^{i}=\frac{2 n^{2}-\delta(n-1) n}{2 n^{2}-\delta(n-1)^{2}}$ and offers $\frac{2 \delta}{2 n^{2}-\delta(n-1)^{2}}$ to $\frac{n-1}{2}$ legislators at random.

Notice that the first part of Proposition 2 denotes the both collective and particularistic (mixed) dimensions of the equilibrium, and the second part of the proposition 2 denotes the only particularistic dimension of the equilibrium. In the mixed part of the equilibrium, if legislators expect to receive both private and public benefits from bargaining process, they exert effort to increase their probability of recognition. Since all legislators expect to receive same amount of private and public benefits, they exert the same level of effort. Thus, they are equally likely to make a proposal in the equilibrium. We also observe that $\frac{\partial y}{\partial \delta}>0, \frac{\partial y}{\partial n}<0$, and $\frac{\partial y}{\partial \alpha}>0$. The first condition implies that as legislators become more patient, they become more willing to vote "no" for the current proposal and they become more willing to wait for being the next proposer. To prevent this, the current proposal must be more attractive and this is provided through public good spending channel. The second condition directly implies that as the number of the legislator decreases, any coalition member's recognition probability increases for the next stages. Therefore, the current proposal must be more attractive to the public good spending to prevent possible delays. The third condition simply implies that as legislators put a higher value on private good spending, public good spending increases in equilibrium. Because, as $\alpha$ increases, the proposer has to offer more public good spending for the proposal to be accepted by the majority of legislators. Thus, in the mixed part of the equilibrium, the recognized legislator must buy the votes of the minimal winning coalition through public good spending. 
The main idea of the second part of Proposition 2 is that if legislators expect to receive only private benefits from bargaining process, they exert effort to increase their probability of recognition. Since all legislators are symmetric, they expend the same level of effort and hence, legislators' recognition probabilities become the same. Notice that even though effort is costly, zero effort for recognition can not be an equilibrium if the legislators expect to receive private benefits.

We can also provide comparative statistics related to optimal effort levels. In the mixed part of the equilibrium (Proposition 2.i), we have $\frac{\partial e_{\text {mixed }}}{\partial n}<0, \frac{\partial e_{\text {mixed }}}{\partial \delta}<0$ and $\frac{\partial e_{\text {mixed }}}{\partial \alpha}>0$. The first condition implies that as the number of legislators increases, recognition probability directly decreases due to symmetry. Thus, as $n$ increases, optimal effort level decreases. The second condition implies that as patience levels increase legislators expect to receive higher benefits which also increases the probability of being excluded from the minimal winning coalition. Thus, in the symmetric case, we have always $\frac{\partial e_{\text {mixed }}}{\partial \delta}<0$. The last condition states that as public good spending is highly valued, then private good spending is provided in smaller amounts in equilibrium resulting a decrease in the optimal effort level. In the particularistic part of the equilibrium (Proposition 2.ii), we have $\frac{\partial e^{\prime}}{\partial n}<0, \frac{\partial e^{\prime}}{\partial \delta}<0$, and $\frac{\partial e^{\prime}}{\partial \alpha}>0$. The intuition behind the first and second conditions are the same as the mixed part of the equilibrium. The last condition states that as private good spending is highly valued, then the value of being the proposer gets higher and legislators expect to receive higher private benefits resulting an increase in the optimal effort levels.

\section{ASYMMETRIC CASE}

In this section, we assume without loss of generality that legislators have different $\alpha$ valuations. We concentrate on the simplest case of a diverse legislature and we assume that legislators are risk-neutral. 


\subsection{Diverse Legislature}

We assume that legislature is composed of two types of legislators. Let $A$ denote the set of type 1 legislators and $B$ denote the set of type 2 legislators where

$$
A:=\left\{i \in N \mid \alpha_{i}=\alpha_{c}=0\right\} \text { and } B:=\left\{j \in N \mid \alpha_{j}=\alpha_{p}=1\right\}
$$

The set $A$ denotes the agents who want to distribute the whole surplus on the collective dimension (public good dimension) and the set $B$ denotes the legislators who want to distribute the whole surplus on the particularistic dimension (private good dimension). Note that $N=A \cup B$ and $A \cap B=\varnothing$ and there are two opposing political groups. All the legislators have the same characteristics except the valuations $\alpha$ on private and public good dimensions. Note that our model provides the most extreme case in which two types of legislators have completely different valuations. We show that both ideological and distributive decisions exist in the equilibrium under some conditions. Therefore, it can be inferred that when we relax the general structure of the legislature, it would be still possible to see both ideological and distributive decisions in the equilibrium.

Let $|N|=n$ and $|A|=m$. Suppose that any $i \in A$ exerts the effort level $e_{i}$ and any $i \in B$ exerts the effort level $e_{j}$ where $e_{i} \in \mathbb{R}^{+} \cup\{0\}$ for $\left.i \in\{1,2\}\right|^{2}$ Thus, recognition probabilities for two types of legislators can respectively be defined as

$$
\frac{e_{i}}{m e_{i}+(n-m) e_{j}} \text { and } \frac{e_{j}}{m e_{i}+(n-m) e_{j}} \text {. }
$$

Note that legislators exerting higher levels of effort expect to receive a higher prize. Thus, the recognized legislator does not include the legislators exerting higher efforts in the minimum winning coalition due to their higher costs. We first show that each legislator

\footnotetext{
${ }^{2}$ Even if legislators have same marginal costs, their effort levels differ due to legislators' valuations $\alpha$ on private and public good dimensions.
} 
exerts positive effort levels in the equilibrium.

Proposition 3: In a diverse legislature, each type of legislator exerts positive effort in the equilibrium regardless of the composition of the legislature.

Proposition 3 states that each legislator has an incentive to exert positive effort. This is reasonable since there is a conflict of interest between two types of legislators and being a proposer increases the chance of designing a better proposal for the proposer. Without exerting strictly positive effort, legislators' stage utility levels become strictly less than their expected utilities.

In the next propositions, we characterize the equilibrium proposals which specify the allocation of private and public goods in a diverse legislature.

Proposition 4: If the majority is composed of collective-leaning (Type I) legislators and if any $i \in A$ is recognized, then legislator $i$ proposes no private good to any legislator and puts the entire surplus into public good. If any $j \in B$ is recognized, then legislator $j$ proposes

$$
x_{j}^{j}=\frac{\left(1-\delta+\delta k e_{i}^{*}\right)\left(m e_{i}^{*}+(n-m) e_{j}^{*}\right)}{m e_{i}^{*}+(1-\delta)(n-m) e_{j}^{*}}
$$

as private good for herself and gives no private good to any other legislator. Furthermore, legislator $j$ offers

$$
y^{j}=\frac{\delta e_{i}^{*}\left(m\left(1-k e_{i}^{*}\right)-k e_{j}^{*}(n-m)\right)}{m e_{i}^{*}+(1-\delta)(n-m) e_{j}^{*}}
$$

as public good.

Note that the decision $d$ is implemented in the first session. Moreover, due to its complicated structure, we omit the explicit form of $e_{i}^{*}$ and $e_{j}^{*}$. It is easy to see that $e_{i}^{*}$ and $e_{j}^{*}$ are the unique effort levels which can be found by classical fixed-point arguments. Also note that effort levels must be bounded above such that $e_{i} \in\left(0, \frac{(1-\delta)(n-m)}{(n-\delta n+\delta m) k}\right]$ and 
$e_{j} \in\left(0, \frac{(1-\delta) m}{(n-m)(n-\delta n+\delta m) k}\right]$. Next, we give a numerical example which presents the relationship between optimal allocations, effort levels, size of the legislature and legislators' patience levels.

Example 1: Suppose there are two collective (Type I) and one distributive (Type II) agents in a legislature. It is clear that if any collective legislator is recognized, then the game ends immediately with the optimal allocations $x^{*}=0$, and $y^{*}=1$. The following table represents the optimal allocations and effort levels when the distributive legislator is recognized while the legislators' patience levels change.

Table 1

\begin{tabular}{|c|c|c|c|}
\hline & $\mathrm{k}=1$ & $\mathrm{k}=1$ & $\mathrm{k}=1$ \\
\hline & $\delta=0.1$ & $\delta=0.4$ & $\delta=0.6$ \\
\hline$e_{i}^{*}$ & 0.214404 & 0.184262 & 0.154617 \\
\hline$e_{j}^{*}$ & 0.221976 & 0.216249 & 0.202817 \\
\hline$y *$ & 0.04602 & 0.209341 & 0.353615 \\
\hline$x^{*}$ & 0.95398 & 0.790659 & 0.646385 \\
\hline
\end{tabular}

As legislators become more patient, optimal effort level gets smaller and smaller due to its marginal cost. In all three cases, we see that $e_{i}^{*}<e_{j}^{*}$ due to the fact that the majority of legislators are collective-leaning. Since they have the majority, we expect to see that they exert less effort than the distributive legislator. Nonetheless, this is not true in all possible cases. As we show in table 2 (example 2), even though majority consists of collective legislators, collective legislators exert higher effort levels than distributive ones unless their discount rates are not too high. This feature is directly pertinent to composition of majority and majority power with legislators' patience level. Besides, one of the most important outcomes of this particular and the following example is that distributive legislator may have a chance to get almost the whole surplus as a private good when the agents are impatient. However, as legislators become more patient, the optimal allocation for private 
good dimension declines. This is due to the fact that as agents become more patient, exerting effort becomes much more costly, and hence optimal effort levels decrease. Thereby, the total amount of private good allocated to the distributive legislator decreases.

Example 2: In this example, we find optimal effort levels and allocations of private and public goods while the number of the legislators changes. We assume that majority of the legislature consists of collective ones. Therefore, if any collective legislator is recognized, then the game ends with the optimal allocations $x^{*}=0$, and $y^{*}=1$. Thus, the following tables represent the case in which the distributive legislator is recognized. Note that marginal cost $k=1$ is fixed and the same for all legislators.

Table 2

\begin{tabular}{|c|c|c|c|c|}
\hline & $m=4, n=7$ & $m=4, n=7$ & $m=4, n=7$ & $m=4, n=7$ \\
\hline & $\delta=0.1$ & $\delta=0.4$ & $\delta=0.6$ & $\delta=0.9$ \\
\hline$e_{i}^{*}$ & 0.151303 & 0.11951 & 0.09137272 & 0.00751064 \\
\hline$e_{j}^{*}$ & 0.0514808 & 0.0435805 & 0.0351893 & 0.00802247 \\
\hline$y^{*}$ & 0.06587 & 0.291317 & 0.474518 & 0.885965 \\
\hline$x^{*}$ & 0.93413 & 0.708683 & 0.525482 & 0.114035 \\
\hline
\end{tabular}


Table 3

\begin{tabular}{|c|c|c|c|c|}
\hline & $m=14, n=15$ & $m=14, n=15$ & $m=14, n=15$ & $m=14, n=15$ \\
\hline & $\delta=0.1$ & $\delta=0.4$ & $\delta=0.6$ & $\delta=0.9$ \\
\hline$e_{i}^{*}$ & 0.0570675 & 0.0403743 & 0.0280757 & 0.00075 \\
\hline$e_{j}^{*}$ & 0.0574529 & 0.04151023 & 0.0292949 & 0.0008 \\
\hline$y^{*}$ & 0.088176 & 0.366515 & 0.565054 & 0.885965 \\
\hline$x^{*}$ & 0.911824 & 0.633485 & 0.434946 & 0.114035 \\
\hline
\end{tabular}

Even though the majority consists of collective legislators in both Table 2 and Table 3, both group members exert different effort level in each table. The main discrepancy arises from the majority power of the majorities. What we mainly address is that while $57.14 \%$ of the total number of the legislators represents the majority in Table 2; on the other hand, this ratio is much more dense, $93.3 \%$, in Table 3 . The robustness of the majority causes to exert less effort for the minority, and this constitutes different optimal allocations of both public good and private good in table 2 and Table 3. It is obvious that robustness of the majority in Table 2 is less than table 3. In Table 2, as discount rate increases, optimal effort levels not only decrease in equilibrium but also recognition process converges to the exogenous model. However, in Table 3 where the robustness of the majority is almost perfect, our model directly behaves like a exogenous model with very low optimal effort levels. Therefore, we can state that as the robustness of the majority and discount rate increase, recognition process converges to the exogenous recognition model.

In the next proposition, we state the possible ideological and distributive decisions when the majority of legislature is composed of distributive legislators.

Proposition 5: Suppose the majority of the legislature is composed of distributive 
legislators. If any $i \in A$ is recognized, then legislator $i$ proposes

$$
x=\frac{2(n-m) \delta e_{j}^{*}\left(1-k\left(m e_{i}^{*}+(n-m) e_{j}^{*}\right)\right)}{2(n-m)\left(m e_{i}^{*}+(n-m) e_{j}^{*}\right)-\delta(n+1-2 m) m e_{i}^{*}}
$$

private good to $\frac{n+1-2 m}{2}$ distributive legislators and put

$$
y=1-\left(\frac{n+1-2 m}{2}\right) x=1-\frac{\delta(n+1-2 m)(n-m) e_{j}^{*}\left(1-k\left(m\left(e_{i}^{*}-e_{j}^{*}\right)+n e_{j}^{*}\right)\right)}{\delta m(n+1-2 m) e_{i}^{*}-2(n-m)\left(m\left(e_{i}^{*}-e_{j}^{*}\right)+n e_{j}^{*}\right)}
$$

to public good dimension. If any $j \in B$ is recognized, then legislator $j$ proposes

$$
x=\frac{2(n-m) \delta e_{j}^{*}\left(1-k\left(m e_{i}^{*}+(n-m) e_{j}^{*}\right)\right)}{2(n-m)\left(m e_{i}^{*}+(n-m) e_{j}^{*}\right)-\delta(n+1-2 m) m e_{i}^{*}}
$$

to $\frac{n-1}{2}$ other distributive legislators and keeps

$$
x_{j}^{j}=1-\left(\frac{n-1}{2}\right) x=1-\frac{\delta(n-1)(n-m) e_{j}^{*}\left(k\left(m\left(e_{i}^{*}-e_{j}^{*}\right)+n e_{j}^{*}\right)-1\right)}{\delta m(n+1-2 m) e_{i}^{*}-2(n-m)\left(m\left(e_{i}^{*}-e_{j}^{*}\right)+n e_{j}^{*}\right)}
$$

for herself with no public good dimension in equilibrium.

Similar to Proposition 4, decision $d$ is implemented in the first session. Since we are dealing with the extreme case in which majority consists of distributive legislators, collective ones must propose a mixed proposal containing both dimensions. On the other hand, any recognized distributive legislator directly proposes a pure particularistic (distributive-or private good) proposal which contains no public good dimension. As in Proposition 4, effort levels must be bounded above such that $e_{i} \in\left(0, \bar{e}_{i}\right], e_{j} \in\left(0, \overline{e_{j}}\right]$. Proposition 5 implies that when the composition of legislature becomes more homogeneous, it would be easy to have an agreement consisting of both ideological and distributive decisions since our model considers only two different political groups which are at the extremes. Even for this extreme case, we observe that both decisions could be reached in the equilibrium. In that sense, as the 
difference of $\left|\alpha_{p}-\alpha_{c}\right|$ decreases, we also expect to see equilibrium allocations containing both dimensions. As it can be seen from Proposition 5, amount of the private good which is given to unrecognized distributive legislators who are in the minimum winning coalition is the same regardless of the recognized legislator. It mainly occurs due to the fact that legislators' positions are located at the extreme ideological dimensions, $\alpha_{p}=1$ and $\alpha_{c}=0$.

\section{CONCLUDING REMARKS}

In this paper, we combine bargaining in legislatures and rent-seeking contest literature to analyze the sequential bargaining game over private and public goods with endogenous recognition. We show that legislators can exert effort to be the proposer and make proposals in both dimensions depending on legislative preferences. When all legislators are collectiveleaning, there is no conflict of interests in the legislature so that exerting effort becomes an unproductive activity for legislators. However, if legislators prefer to obtain private benefits, they exert effort in the stationary equilibrium. While the optimal effort levels are positively correlated with the valuation of private good spendings, $\alpha$, it is negatively correlated with the number of legislators and legislators' level of patience. In an asymmetric legislature, we show that any type of legislator exerts positive effort in the equilibrium regardless of the composition of the legislature.

\section{References}

[1] Austen-Smith, D. \& Banks, J., (1988). Elections, Coalitions, and Legislative Outcomes. American Political Science Review, 82(2), 409-422.

[2] Banks, J. \& Duggan, J. (2000). A Bargaining Model of Collective Choice. American Political Science Review, 94(1), 73-88. 
[3] Baron, D. \& Ferejohn, J. (1989). Bargaining in Legislatures. American Politic Science Review, 83, 1181-1206.

[4] Debreu, G. (1952). A Social Equilibrium Existence Theorem. Proceedings of the National Academy of Sciences, 38, 886-893.

[5] Fan, K. (1952). Fixed-point and Minimax Theorems in Locally Convex Topological Spaces. Proceedings of the National Academy of Sciences USA, 38, 121-126.

[6] Fudenberg, D. \& Tirole, J. (1991). Game Theory. Cambridge, Massachusetts: MIT Press.

[7] Glicksberg, I.L., (1952). A Further Generalization of the Kakutani Fixed Point Theorem, with Applications to Nash Equilibrium Points. Proceedings of the American Mathematical Society, 3, 170-174.

[8] Jackson, M. \& Moselle, N. (2002). Coalition and Party Formation in a Legislative Voting Game. Journal of Economic Theory, 103, 49-87.

[9] Merlo, A. \& Wilson, C. (1995). A Stochastic Model of Sequential Bargaining with Complete Information. Econometrica, 63, 371-399.

[10] Rubinstein, A. (1982). Perfect Equilibrium in a Barganing Model. Econometrica, 50, 97-109.

[11] Szidarovszky, F. \& Okuguchi, K. (1997). On the Existence and Uniqueness of Pure Nash Equilibrium in Rent-Seeking Games. Games and Economic Behavior, 18(1) $135-140$

[12] Tullock, G. (2001). Efficient Rent Seeking. In: Lockard, A.A, Tullock, G., Eds., Efficient Rent Seeking, Springer, Boston, MA, 3-16.

[13] Volden, C. \& Wiseman, A. (2007). Bargaining in Legislatures over Particularistic and Collective Goods. The American Political Science Review, 101, 79-92. 
[14] Yildirim, H. (2007). Proposal Power and Majority Rule in Multilateral Bargaining with Costly Recognition. Journal of Economic Theory, 136 167-196.

[15] Yildirim, H. (2010). Distribution of Surplus in Sequential Bargaining with Endogenous Recognition. Public Choice, 142, 41-57. 


\section{APPENDIX}

The main idea of for the proofs of Proposition 1 and 2 relies on the fact that there are mainly three types of decisions which can be supported in the symmetric equilibrium for different levels of $\alpha$ as in Volden and Wiseman (2007). Before starting to proofs we state a lemma which is relatively standard in the rent-seeking literature. A similar result is also stated in Yildirim (2007). We provide the proof for completeness.

LEMMA 1: In the one-shot legislative game in which

$$
p_{i}(e)=\left\{\begin{array}{cc}
\frac{e_{i}}{\sum_{j \in N} e_{j}} & \text { if } e \neq \overrightarrow{0} \\
\frac{1}{n} & \text { if } e=\overrightarrow{0} .
\end{array}\right.
$$

and the recognized legislator receives an exogenous prize $\Pi_{i}>0$, then there exists a unique pure strategy equilibrium such that $e_{i} \geqslant e_{j}>0$ (with strict inequality whenever $\frac{k_{i}}{\Pi_{i}}>\frac{k_{j}}{\Pi_{j}}$ ) and $p_{i}=1-(n-1) \frac{\frac{k_{i}}{\Pi_{i}}}{\sum_{j} \frac{k_{j}}{\Pi_{j}}}$.

Proof: First, notice that $e_{i}=0$ for all $i \in N$ can not be an equilibrium. The expected equilibrium payoff for legislator $i$ satisfies the following program:

$$
v_{i}=\max _{e_{i} \geqslant 0}\left\{p_{i}(e) \Pi_{i}-k_{i} e_{i}\right\}
$$

Taking the derivative of the terms inside the brackets yields

$$
\frac{\partial p_{i}(e)}{\partial e_{i}} \Pi_{i}-k_{i} \leqslant 0\left(=0 \text { if } e_{i}>0\right)^{3}
$$

This implies

$$
\frac{\sum_{j \neq i} e_{j}}{\left(\sum_{j} e_{j}\right)^{2}}=\frac{1-p_{i}}{\sum_{j} e_{j}}=\frac{k_{i}}{\Pi_{i}}
$$

\footnotetext{
${ }^{3}$ It is easy to see that the second order condition holds.
} 
which is equivalent to $\sum_{j} e_{j}=\frac{(n-1)}{\sum \frac{k_{i}}{\Pi_{i}}}$. Therefore,

$$
p_{i}=1-(n-1) \frac{\frac{k_{i}}{\Pi_{i}}}{\sum_{j} \frac{k_{j}}{\Pi_{j}}}
$$

For a proof of uniqueness for the general case, see Szidarovsky and Okuguchi (1997)

\section{Proof of Proposition 1:}

If a legislator $i$ is recognized in session $t$, she chooses a proposal according to the following program:

$$
d^{i} \in \operatorname{argmax}_{d} \alpha x_{i}^{i}+(1-\alpha) y^{i}
$$

subject to $\alpha x_{j}^{i}+(1-\alpha) y^{i}=\delta v_{j} \forall j \in C$ where $|C|=\frac{n+1}{2}$ and $y^{i}+\sum_{k \in N} x_{k}^{i} \leq 1$. Notice that $\alpha x_{i}^{i}+(1-\alpha) y^{i}=(2 \alpha-1) x_{i}^{i}+(1-\alpha)+(\alpha-1) \sum_{k \in C \backslash\{i\}} x_{k}^{i}$. This implies that $d^{i}=(1,0, \ldots, 0)$ if $\alpha \in\left[0, \frac{1}{2}\right]$. Therefore, being recognized does not affect the expected payoffs since approved proposal involves only public good dimension. Then, legislator $i$ 's continuation payoff is

$$
v_{i}=\max _{e_{i}} p_{i}(e)(1-\alpha)+\left(1-p_{i}(e)\right)(1-\alpha)-k e_{i}
$$

This implies $e_{i}=0 \forall i \in N$. Hence, legislators do not exert effort (which is costly) and recognition probabilities are identical. Therefore, legislator who is recognized in the first session will put all resources to the public good dimension and this decision will be approved by all legislators.

\section{Proof of Proposition 2:}

Suppose legislator $i$ is recognized in the first session, and he keeps $x_{i}^{i}$ for himself and puts $y^{i}=1-x_{i}^{i}$ to the public good. Suppose this decision is rejected by a majority. Let $j$ be a member of coalition who voted no in the first session. Then, he expects that a decision 
can be approved in the second session if and only if $x_{j}^{j}=x_{i}^{i}-\epsilon_{j}$ and $y^{j}=y^{i}+\epsilon_{j}$ where $\epsilon_{j} \in(0,1)$. By stationary, legislator $j$ would make the same decision if he is recognized in the first session and the decision is accepted. This implies that legislator $i$ 's decision is not optimal and can not be a part of equilibrium since he is better off by making a proposal same as legislator $j$ 's proposal in the first session. Therefore, the game ends in the first session and $x_{i}^{i}=x_{j}^{j}=x$ for all $i, j \in N$. Then, the legislative game can be thought as one-shot game with a fixed prize $(\Pi=\alpha x+(1-\alpha)(1-x))$. From Lemma $1, p_{i}=\frac{1}{n}$ and thus $e_{i}=e_{j}=e=\frac{(n-1)}{n^{2} k} \Pi>0$ for all $i \in N$. At the voting stage non-proposer $j$ votes yes if and only if :

$$
\begin{gathered}
(1-\alpha)(1-x) \geqslant \delta p_{j}(e) \alpha x+\delta(1-\alpha)(1-x)-\delta k e_{j} \\
(1-\alpha)(1-x) \geqslant \delta p_{j}(e) \alpha x+\delta(1-\alpha)(1-x)-\delta \frac{(n-1)}{n^{2}}(\alpha x+(1-\alpha)(1-x))
\end{gathered}
$$

This implies

$$
x \leq \frac{(1-\alpha)\left(n^{2}(1-\delta)+\delta(n-1)\right.}{\delta \alpha+(1-\alpha)\left(n^{2}(1-\delta)+\delta(n-1)\right)}
$$

Then, to maximize his utility legislator $i$ sets

$$
\begin{aligned}
& x=\frac{(1-\alpha)\left(n^{2}-\delta\left(n^{2}-n+1\right)\right)}{\delta \alpha+(1-\alpha)\left(n^{2}(1-\delta)+\delta(n-1)\right)} \\
& y=\frac{\delta \alpha}{\delta \alpha+(1-\alpha)\left(n^{2}(1-\delta)+\delta(n-1)\right)}
\end{aligned}
$$

Moreover from Lemma 1 :

$$
e=\frac{(n-1)}{n^{2} k}\left(\frac{\alpha(1-\alpha)\left(n^{2}(1-\delta)+\delta n\right)}{\delta \alpha+(1-\alpha)\left(n^{2}(1-\delta)+\delta(n-1)\right.}\right)>0
$$

Notice that this decision is approved unanimously in the first session. Then, legislator $i$ 's 
utility is given by,

$$
U_{I}=\Pi\left(1-\frac{n-1}{n^{2}}\right)
$$

In pure private good dimension ; i.e. $\alpha \in\left(\alpha_{p}, 1\right]$, suppose legislator $i$ keeps $x_{i}^{i}=1-x\left(\frac{n-1}{2}\right)$ for himself, puts $y^{i}=0$ to the public good and divides the remaining surplus $1-x_{i}^{i}$ between $\frac{n-1}{2}$ legislators at random. By stationary, the legislative game can be thought as one-shot game with a prize $\left(\Pi=\alpha x_{i}^{i}\right)$. From Lemma $1, e_{i}=e_{j}=\frac{(n-1)}{n^{2} k} \Pi^{\prime}>0$ and thus $p_{i}=\frac{1}{n}$ for all $i \in N$. By symmetry, $x_{i}^{i}=x_{j}^{j}=1-\left(\frac{n-1}{2}\right) x$ for all $i, j \in N$. This implies that the model reduces to Baron and Ferejohn (1989). We state the rest of the proof for completeness. At the voting stage non-proposer $j$ votes yes if and only if :

$$
\alpha x \geqslant \delta p_{j}(e) \alpha\left(1-\frac{n-1}{2} x\right)+\delta\left(1-p_{j}(e)\right) \frac{1}{2} \alpha x-\delta k e_{j}
$$

This implies $x \geqslant \frac{2 \delta}{2 n^{2}-\delta(n-1)^{2}}$. Then, to maximize utility legislator $i$ sets $x=\frac{2 \delta}{2 n^{2}-\delta(n-1)^{2}}$. Notice that this decision is approved by a majority in the first session and optimal effort level directly becomes (From Lemma 1) :

$$
e=\frac{\alpha(n-1)}{n^{2} k}\left(1-\frac{(n-1) \delta}{2 n^{2}-\delta(n-1)^{2}}\right)>0
$$

Then, legislator $i$ 's utility is given by,

$$
U_{I I}=\Pi^{\prime}-k e^{\prime}=\Pi^{\prime}\left(1-\frac{n-1}{n^{2}}\right) .
$$

Now, we will find the cut-off value $\alpha_{p}$ by comparing the proposer's stage utility levels. Then, $\alpha_{p}$ is given by the following equation:

$$
U_{I I}=\Pi^{\prime}-k e^{\prime}=\Pi^{\prime}\left(1-\frac{n-1}{n^{2}}\right) \geq U_{I}=\Pi\left(1-\frac{n-1}{n^{2}}\right) \Longleftrightarrow
$$




$$
\Pi^{\prime} \geq \Pi
$$

This implies,

$$
\alpha_{p}=\frac{n(1+\delta+n(1-\delta))}{(3+n) n-\delta\left(n^{2}-1\right)} .
$$

Proof of Proposition 3: We show that legislators have incentives to exert positive effort when the other type of legislators exerts zero effort.

Case 1: The majority consists of legislators who support public good provision i.e., $m>\frac{n-1}{2}$. First, suppose both type of legislators exert zero effort i.e., $\left(e_{i}, e_{j}\right)=(0,0) \forall i \in$ $A$ and $\forall j \in B$. For any legislator $j \in B$, she takes $x$ for herself and gives $1-x$ for the supporters of public good provision. At the critical voting stage non-proposer legislator $i \in A$ will support the decision of any legislator $j \in B \Longleftrightarrow$

$$
(1-x) \geq \delta\left(\frac{m}{n}+\frac{(n-m)}{n}(1-x)\right)
$$

This implies: $x=\frac{n-\delta n}{n-\delta n+\delta m}$ and $y=\frac{\delta m}{n-\delta n+\delta m}$. Then, expected utility for the legislators $j \in B$ :

$$
E U_{j}=\frac{(n-m)}{n}\left(\alpha_{p} \frac{1}{n-m} x\right)+\frac{m}{n} \alpha_{p} 0=\frac{1-\delta}{n-\delta n+\delta m}
$$

Similarly, expected utility for the legislators $i \in A$ :

$$
E U_{i}=\frac{m}{n}+\frac{\delta(n-m) m}{n(n-\delta n+\delta m)}
$$

Now, we look for whether there exists an incentive for any legislator to exert positive effort when both types exert 0 effort initially. If $e_{i}=0 \forall i \in A$, then any legislator $j \in B$ exerts 
$e_{j}>0$ and distributive legislator, $j \in B$, will be recognized with certainty. Then, to exert positive effort we must have the following: $\frac{n-\delta n}{(n-m)(n-\delta n+\delta m)}-k e_{j} \geq \frac{1-\delta}{n-\delta n+\delta m}$. Then, $e_{j} \in\left(0, \frac{(1-\delta) m}{(n-m)(n-\delta n+\delta m) k}\right]$. It is clear that in this interval, we find that exerting positive effort makes the legislator $j \in B$ better-off while $e_{i}=0 \forall i \in A$.

If $e_{j}=0 \forall j \in B$, any legislator $i \in A$ exerts $e_{i}>0$ and any collective legislator, $i \in A$, will be recognized with certainty. Note that there exists only ideological dimension in the equilibrium since majority consists of legislators who support public-good provision. Then, to exert positive effort we must have the following: $1-k e_{i} \geq \frac{m}{n}+\frac{\delta(n-m) m}{n(n-\delta n+\delta m)}$. Then, $e_{i} \in\left(0, \frac{(n-m)(1-\delta)}{(n-\delta n+\delta m) k}\right]$. Obviously, in this interval, we find that exerting positive effort makes legislator $i \in A$ better-off while $e_{j}=0 \forall j \in B$. Thus, exerting positive effort makes each type of legislator better-off if the other group exerts zero effort.

Therefore, we must have $\left(e_{i}, e_{j}\right) \neq(0,0) \forall i \in A$ and $\forall j \in B$. Then, for any $i \in A$,

$$
E U_{i}=\frac{m e_{i}}{m e_{i}+(n-m) e_{j}}+\frac{(n-m) e_{j}}{m e_{i}+(n-m) e_{j}}\left(\frac{\delta e_{i}\left[m\left(1-k e_{i}\right)-k e_{j}(n-m)\right]}{m e_{i}+(1-\delta)(n-m) e_{j}}\right)-k e_{i}
$$

and for any $j \in B$ :

$$
E U_{j}=\frac{e_{j}}{m e_{i}+(n-m) e_{j}}\left(\frac{\left(1-\delta+\delta k e_{i}\right)\left(m e_{i}+(n-m) e_{j}\right)}{m e_{i}+(1-\delta)(n-m) e_{j}}\right)-k e_{j}{ }_{4}^{4}
$$

Given the expected payoffs, it is clear to see that $\exists\left(e_{i}, e_{j}\right) \neq(0,0)$ such that $E U_{i}\left(e_{i}, e_{j}=\right.$ $\epsilon)>E U_{i}\left(0, e_{j}=\epsilon\right)$ and $E U_{j}\left(e_{i}=\epsilon^{\prime}, e_{j}\right)>E U_{j}\left(e_{i}=\epsilon^{\prime}, 0\right)$ where $\epsilon$ and $\epsilon^{\prime}$ are very small positive real numbers.

Case 2: If majority consists of legislators who support private good provision i.e, $m<\frac{n-1}{2}$. First, suppose both type of legislators exert zero effort i.e, $\left(e_{i}, e_{j}\right)=(0,0) \forall i \in$

\footnotetext{
${ }^{4}$ The derivation of $E U_{i}$ and $E U_{j}$ are explicitly stated in the proof of Proposition 4.
} 
$A$ and $\forall j \in B$. For any legislator $j \in B$ is recognized, then she gives $x^{\prime \prime}$ particularistic goods to $\frac{n-1}{2}$ other legislators who support private good allocation and keeps $x^{P}=1-$ $\left(\frac{n-1}{2}\right) x^{\prime \prime}$. For any legislator $i \in A$ is recognized, then she gives $x^{\prime}$ particularistic goods to $\frac{n+1-2 m}{2(n-m)}$ distributive legislators and puts $y=1-\left(\frac{n+1-2 m}{2(n-m)}\right) x^{\prime}$ towards collective. At the critical voting stage, if collective one is recognized, non-proposer distributive legislator will vote as "Yes" if and only if

$$
\alpha_{p} x^{\prime}+\left(1-\alpha_{p}\right) y \geq \delta\left(\frac{1}{n} x^{P}+\left(\frac{n-m-1}{n}\right) \frac{(n-1)}{2(n-m-1)} \alpha_{p} x^{\prime \prime}+\frac{m}{n} \frac{(n+1-2 m)}{2(n-m)} x^{\prime}\right)
$$

Also note that $\alpha_{p}=1$ and in equilibrium we must have $\alpha_{p} x^{\prime}+\left(1-\alpha_{p}\right) y=\alpha_{p} x^{\prime \prime}$ and since $\alpha_{p}=1$, we have $x^{\prime}=x^{\prime \prime}$. Then, optimality requires that:

$$
\begin{gathered}
x^{\prime}=\frac{2 \delta(n-m)}{2(n-m) n-\delta m(n+1-2 m)}=x^{\prime \prime} \\
x^{P}=\frac{2(n-m) n-\delta m(n+1-2 m)-\delta(n-m)(n-1)}{2(n-m) n-\delta m(n+1-2 m)}
\end{gathered}
$$

and $y=\frac{2(n-m) n-\delta n(n+1-2 m)}{2(n-m) n-\delta m(n+1-2 m)}$. Then expected utility for legislators $i \in A$,

$$
E U_{i}^{0}=\frac{m}{n} y+\frac{(n-m)}{n} .0=\frac{2 m(n-m)-\delta m(n+1-2 m)}{2(n-m) n-\delta m(n+1-2 m)}
$$

Similarly, expected utility for legislators $j \in B$,

$$
E U_{j}^{0}=\frac{m(n+1-2 m)}{2 n(n-m)} x^{\prime}+\frac{1}{n} x^{P}+\frac{(n-m-1)}{n} \frac{(n-1)}{2(n-m-1)} x^{\prime \prime}=\frac{2(n-m)}{2(n-m) n-\delta m(n+1-2 m)}
$$

Now, we check whether there exists any incentive for any legislator to exert positive effort when the other type exerts zero effort initially. If $e_{i}=0 \forall i \in A$, any legislator $j \in B$ exerts $e_{j}>0$ and, distributive legislator, $j \in B$, will be recognized directly. Then, to exert positive effort we must have the following: 


$$
\frac{x^{P}}{(n-m)}+\frac{(n-m-1)}{(n-m)}\left(\frac{(n-1)}{2(n-m-1)} x^{\prime}\right)-k e_{j} \geq E U_{j}^{0}=\frac{2(n-m)}{2(n-m) n-\delta m(n+1-2 m)}
$$

Then, when $e_{j} \in\left(0, \frac{2(n-m) m-\delta m(n+1-2 m)}{k B(n-m)}\right)$ where $B=2(n-m) n-\delta m(n+$ $1-2 m$ ), distributive legislator will exert positive effort while the collective ones are inactive.

If $e_{j}=0 \forall j \in B$, then any legislator $i \in A$ exerts $e_{i}>0$ and collective ones will be recognized directly. Then, to exert positive effort we must have the following:

$$
\frac{2(n-m) n-\delta n(n+1-2 m)}{2(n-m) n-\delta m(n+1-2 m)}-k e_{i} \geq \frac{m}{n} y=E U_{i}^{0}=\frac{2 m(n-m)-\delta m(n+1-2 m)}{2(n-m) n-\delta m(n+1-2 m)}
$$

When $e_{i} \in\left(0, \frac{B(n-m)}{k n}\right)$ where $B=2(n-m) n-\delta m(n+1-2 m)$, then collective legislator will exert positive effort while the distributive ones are inactive. As a result, each type of legislator becomes better-off by exerting positive effort if the other type of legislator exerts zero effort. Thus, we must have $\left(e_{i}, e_{j}\right) \neq(0,0) \forall i \in A$ and $\forall j \in B$. Then, for any $i \in A$ :

$E U_{i}=\frac{m e_{i}}{m e_{i}+(n-m) e_{j}}\left[1-\left(\frac{n+1-2 m}{2}\right) \frac{2(n-m) \delta e_{j}\left[1-k\left(m e_{i}+(n-m) e_{j}\right)\right]}{2(n-m)\left(m e_{i}+(n-m) e_{j}\right)-\delta(n+1-2 m) m e_{i}}\right]-k e_{i}$

and for any $j \in B$ :

$$
\begin{gathered}
E U_{j}=\frac{m e_{i}}{m e_{i}+(n-m) e_{j}}\left[\frac{2(n+1-2 m) \delta e_{j}\left[1-k\left(m e_{i}+(n-m) e_{j}\right)\right]}{2(n-m)\left(m e_{i}+(n-m) e_{j}\right)-\delta(n+1-2 m) m e_{i}}\right] \\
+\frac{(n-m) e_{j}}{m e_{i}+(n-m) e_{j}}\left[\frac{x^{P}}{(n-m)}+\frac{(n-1) x^{\prime}}{2(n-m-1)}\right]-k e_{j} .
\end{gathered}
$$

Given the expected payoffs, it is clear to see that $\exists\left(e_{i}, e_{j}\right) \neq(0,0)$ such that $E U_{i}\left(e_{i}, e_{j}=\right.$ 
$\epsilon)>E U_{i}\left(0, e_{j}=\epsilon\right)$ and $E U_{j}\left(e_{i}=\epsilon^{\prime}, e_{j}\right)>E U_{j}\left(e_{i}=\epsilon^{\prime}, 0\right)$ where $\epsilon$ and $\epsilon^{\prime}$ are very small positive real numbers.

Proof of Proposition 4: Collective legislator is recognized with the probability $\frac{m e_{i}}{m e_{i}+(n-m) e_{j}}$. If collective one is recognized, decision $d$ is accepted by the majority and the game ends in the first session with stage utilities, $U_{i}=1-k e_{i}$ and $U_{j}=-k e_{j}$. Distributive legislator is recognized with the probability $\frac{(n-m) e_{j}}{m e_{i}+(n-m) e_{j}}$. At the critical voting stage, non-proposer collective legislator will say "Yes" if and only if

$$
\left(1-\alpha_{c}\right)(1-x) \geq \delta\left(\frac{m e_{i}}{m e_{i}+(n-m) e_{j}}\left(1-\alpha_{c}\right)+\frac{(n-m) e_{j}}{m e_{i}+(n-m) e_{j}}\left(1-\alpha_{c}\right)(1-x)-k e_{i}\right)
$$

Note that $\alpha_{c}=0$. Therefore, we have

$$
\begin{gathered}
x=\frac{\left(1-\delta+\delta k e_{i}\right)\left(m e_{i}+(n-m) e_{j}\right)}{m e_{i}+(1-\delta)(n-m) e_{j}} \\
y=\frac{\delta e_{i}\left[m\left(1-k e_{i}\right)-k e_{j}(n-m)\right]}{m e_{i}+(1-\delta)(n-m) e_{j}}
\end{gathered}
$$

Note that the game ends in the first session since distributive legislator gives the amount that satisfies continuation value of collective legislators which makes them indifferent between saying yes or no. Now, we show the optimal effort levels $e_{i}^{*}$ and $e_{j}^{*}$ exist. Indeed, intersection point(s) of best response correspondences for each group of legislators is not an empty set. Expected utility for the distributive legislator, denoted by $E U_{i}$;

$$
E U_{i}=\frac{m e_{i}}{m e_{i}+(n-m) e_{j}}+\frac{(n-m) e_{j}}{m e_{i}+(n-m) e_{j}}\left(\frac{\delta e_{i}\left[m\left(1-k e_{i}\right)-k e_{j}(n-m)\right]}{m e_{i}+(1-\delta)(n-m) e_{j}}\right)-k e_{i}
$$


Similarly, expected utility for the distributive, denoted by, $E U_{j}$ :

$$
E U_{j}=\frac{e_{j}}{m e_{i}+(n-m) e_{j}}\left(\frac{\left(1-\delta+\delta k e_{i}\right)\left(m e_{i}+(n-m) e_{j}\right)}{m e_{i}+(1-\delta)(n-m) e_{j}}\right)-k e_{j}
$$

Note that cardinality of strategy sets for each group are infinite since $e_{i} \in\left(0, \frac{(n-m)(1-\delta)}{(n-\delta n+\delta m) k}\right]$, $e_{j} \in\left(0, \frac{(1-\delta) m}{(n-m)(n-\delta n+\delta m) k}\right]$. Then, by Debreu (1952), Fan (1952) and Glicksberg $(1952){ }^{5}, \exists\left(e_{i}^{*}, e_{j}^{*}\right)$ such that intersection of two best-response correspondences are not empty set. Note also that by Proposition 3 , we have $\left(e_{i}, e_{j}\right) \neq(0,0)$. Therefore, we do not have any possible continuity problem.

Proof of Proposition 5: Collective and distributive legislator are recognized with the probabilities $\frac{m e_{i}}{m e_{i}+(n-m) e_{j}}$ and $\frac{(n-m) e_{j}}{m e_{i}+(n-m) e_{j}}$ respectively. If collective one is recognized, she gives $x^{\prime}$ private good to $\left(\frac{n+1-2 m}{2}\right)$ distributive legislators and puts $y=1-\left(\frac{n+1-2 m}{2}\right) x^{\prime}$ to the public good. If distributive legislator is recognized, then she gives $x^{\prime \prime}$ private good to $\left(\frac{n-1}{2}\right)$ other distributive legislators and keeps $x^{P}=1-\left(\frac{n-1}{2}\right) x^{\prime \prime}$ for herself. At the critical voting stage, non-proposer distributive legislator votes yes if and only if:

Case 1: If the collective legislator is recognized:

$$
\begin{aligned}
\alpha_{p} x^{\prime}+\left(1-\alpha_{p}\right) y \geq & \delta\left[\frac{e_{j}}{m e_{i}+(n-m) e_{j}} \alpha_{p} x^{P}+\frac{\left(n-m-1 e_{j}\right)}{m e_{i}+(n-m) e_{j}} \frac{(n-1)}{2(n-m-1)} \alpha_{p} x^{\prime \prime}\right] \\
& +\delta\left[\frac{m e_{i}}{\left.m e_{i}+(n-m) e_{j}\right)} \frac{(n+1-2 m)}{2(n-m)} \alpha_{p} x^{\prime}-k e_{j}\right]
\end{aligned}
$$

\footnotetext{
${ }^{5}$ See Fudenberg and Tirole (1991) for more on the existence theorem.
} 
Case 2: If distributive legislator is recognized:

$$
\begin{gathered}
\alpha_{p} x^{\prime \prime} \geq \delta\left[\frac{e_{j}}{m e_{i}+(n-m) e_{j}} \alpha_{p} x^{P}+\frac{\left(n-m-1 e_{j}\right)}{m e_{i}+(n-m) e_{j}} \frac{(n-1)}{2(n-m-1)} \alpha_{p} x^{\prime \prime}\right] \\
+\delta\left[\frac{m e_{i}}{\left.m e_{i}+(n-m) e_{j}\right)} \frac{(n+1-2 m)}{2(n-m)} \alpha_{p} x^{\prime}-k e_{j}\right]
\end{gathered}
$$

As it can be seen that in equilibrium, we must have :

$$
\alpha_{p} x^{\prime}+\left(1-\alpha_{p}\right) y=\alpha_{p} x^{\prime \prime}
$$

Since $\alpha_{p}=1$, we have $x^{\prime}=x^{\prime \prime}=\frac{2(n-m) \delta e_{j}\left(1-k\left(m e_{i}+(n-m) e_{j}\right)\right)}{2(n-m)\left(m e_{i}+(n-m) e_{j}\right)-\delta(n+1-2 m) m e_{i}}$ with $x^{P}=1-\left(\frac{n-1}{2}\right) x^{\prime}$ and $y=1-\left(\frac{n+1-2 m}{2}\right) x^{\prime}$. Note that the game ends in the first session since both collective and distributive legislators offers the continuation value of other distributive legislators making them indifferent between saying yes or no. Furthermore, by Debreu (1952), Fan (1952) and Glicksberg (1952), $\exists\left(e_{i}^{*}, e_{j}^{*}\right)$ such that intersection of best-response correspondences are not empty set. Note also that by proposition 3, we have $\left(e_{i}, e_{j}\right) \neq(0,0)$. Therefore, we do not have any possible continuity problem. 